\title{
Finite Element Modeling of Thermal Cycling Induced Microcracking in Carbon/Epoxy Triaxial Braided Composites
}

Chao Zhang ${ }^{1}$, Wieslaw K Binienda ${ }^{2}$, Gregory Morscher ${ }^{3}$, Richard E Martin ${ }^{4}$ and Lee W Kohlman ${ }^{5}$

${ }^{1}$ Department of Civil Engineering, University of Akron, 302 Buchtel Common, Akron, Ohio, 44304; email: cz14@zips.uakron.edu

${ }^{2}$ Department of Civil Engineering, University of Akron, 302 Buchtel Common, Akron, Ohio, 44304; email: wieslaw@uakron.edu

${ }^{3}$ Department of Mechanical Engineering, University of Akron, 302 Buchtel Common, Akron, Ohio, 44304; email: gm33@uakron.edu

${ }^{4}$ Department of Mechanical Engineering, Cleveland State University, 2121 Euclid Avenue, Cleveland, Ohio, 44115; email: Richard.e.martin-1@nasa.gov

${ }^{5}$ NASA Glenn Research Center, 21000 Brookpark Road, Cleveland, Ohio, 44135; email: lee.w.kohlman@nasa.gov

\begin{abstract}
The microcrack distribution and mass change in PR520/T700s and 3502/T700s carbon/epoxy braided composites exposed to thermal cycling was evaluated experimentally. Acoustic emission was utilized to record the crack initiation and propagation under cyclic thermal loading between $-55^{\circ} \mathrm{C}$ and $120^{\circ} \mathrm{C}$. Transverse microcrack morphology was investigated using X-ray Computed Tomography. Different performance of two kinds of composites was discovered and analyzed. Based on the observations of microcrack formation, a meso-mechanical finite element model was developed to obtain the resultant mechanical properties. The simulation results exhibited a decrease in strength and stiffness with increasing crack density. Strength and stiffness reduction versus crack densities in different orientations were compared. The changes of global mechanical behavior in both axial and transverse loading conditions were studied.
\end{abstract}

Keywords: Thermal cycles; Microcrack; Finite Element Model; Braided Composite

\section{Introduction}

Carbon fiber/polymer composites are currently widely used in aerospace structures because of their higher strength, light weight, non-corrosive properties, dimensional stability, and possibility of performance-based design. Compared with classical laminated composites, woven and braided composites show excellent throughthickness properties and offer good impact performance. In particular, braided composites with a bias fiber orientation of $\pm 60^{\circ}$ have been reported to show crack initiation and propagation resistance, as well as resist formation of delamination during impact ${ }^{[1]}$.

In some aerospace applications, composite structures may experience cyclic thermal loading. Due to the mismatch of the coefficients of thermal expansion between fiber and resin, large thermal stresses may develop which could lead to 
microcrack formation. This phenomenon has serious implications as to the suitability of composite for intended use in aerospace, particularly for long term performance.

Eselun et al ${ }^{[2]}$ employed $0^{\circ} / \pm 60^{\circ} / 0^{\circ}$ and $\pm 30^{\circ}$ tubes made from GY70 carbon fiber and 934 epoxy resin. His samples were cycled between $24^{\circ} \mathrm{C}$ and -120 or $140^{\circ} \mathrm{C}$ at a rate of $3.6^{\circ} \mathrm{C} / \mathrm{min}$. The behaviors of the materials were evaluated using $\mathrm{X}$ -

rays, acoustic emission, and microscopy. Lafarie-Frenot et $\mathrm{al}^{[3,4,5]}$ did a series of experiments on carbon fiber/epoxy laminates. They observed two kinds of cracks. Transverse cracks were generated across the whole thickness of the specimens. The other kind of cracks was randomly distributed "small cracks" which vary in length from a few fiber diameters to half the thickness of the layer.

Cohen and Hyen ${ }^{[6]}$ used 90/06/90 tubes made from T300-T3-934, T300-P75S934, and T300-P75S-CE339 carbon-fiber and epoxy resins, cycled up to 500 times between $-156^{\circ} \mathrm{C}$ and $93^{\circ} \mathrm{C}$. It was found that the damage was more extensive in 934 epoxy resin composites and included skin/core delamination. Adam et al ${ }^{[9]}$ emulated the effect of a space environment for T700/5208 carbon epoxy resin specimens with various symmetrical lay-ups. He noted that no crack saturation was observed even after 500 cycles. The cracks were found to avoid resin rich areas.

Seehra et $\mathrm{al}^{[7]}$ studied the effects of space environmental conditions on several carbon/epoxy composites. The study showed that the mechanical properties of the composites remain unchanged after the exposure except a slight decrease in strength when tested at low temperature. Shin et $\mathrm{al}^{[8]}$ studied the behavior of graphite/epoxy composite materials under combined environments of which the thermal cycling was defined as a change from $-70^{\circ} \mathrm{C}$ to $100^{\circ} \mathrm{C}$. In this study, he found that the strength and stiffness of the composites after exposure decreased in exponential proportion to increased thermal cycles. Also, the changes in transverse flexural strength and stiffness showed a quicker decrease as compared to other mechanical properties.

In this work, two carbon/epoxy $+60^{\circ} / 0^{\circ} / 60^{\circ}$ triaxial braided composite, T700S/3502 and T700S/PR520, as well as 3502 and PR520 pure resins were exposed to a thermal cycling environment. Acoustic Emission (AE) was used to monitor the crack initiation and propagation. The microcrack formation and physical behaviors for these two composite systems were analyzed and compared. Based on the observations, a finite element analysis (FEA) of a meso-mechanical composite model was developed to study the influence of cracks on mechanical properties of braided composites.

\section{Experimental Study}

Material: Epoxy resins 3502 and PR520 together with 6 layers of Toray T700S triaxial $+60^{\circ} / 0^{\circ} /-60^{\circ}$ braided carbon preform were used to produce composite plates. The composite plates were manufactured as $5.08 \mathrm{~cm} \times 5.08 \mathrm{~cm} \times 0.635 \mathrm{~cm}(2$ in $\times 2$ in $\times 0.25$ in.) thick sheets using a resin transfer molding process. The cure time for $3502 / \mathrm{T} 700 \mathrm{~s}$, at a maximum temperature of $176^{\circ} \mathrm{C}\left(350^{\circ} \mathrm{F}\right)$, was 2 hours and the cure time for PR520/T700s was 2.5 hours at the same temperature.

Thermal Cycling: Figure 1 illustrates the thermal cycle process used in this study. First the temperature was increased from $20^{\circ} \mathrm{C}\left(70^{\circ} \mathrm{F}\right)$ to $121^{\circ} \mathrm{C}\left(250^{\circ} \mathrm{F}\right)$, then 
decreased to $-55^{\circ} \mathrm{C}\left(-65^{\circ} \mathrm{F}\right)$ and returned to $20^{\circ} \mathrm{C}$. The entire cycle lasted about 3 hours.

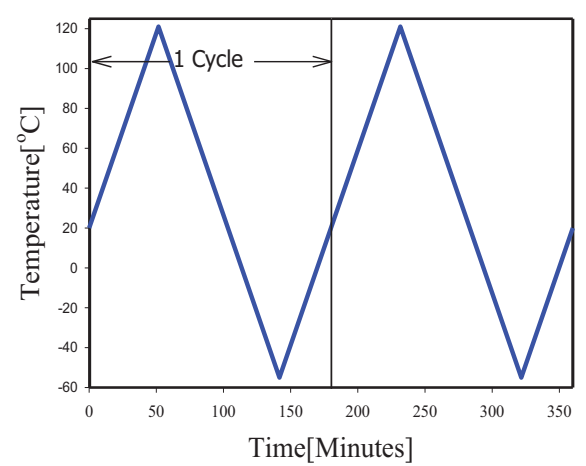

Figure 1: Temperature profile for the thermal cycling experiment

\section{Evaluation of Composites under Thermal Cycling}

\section{Mass and Volume Change}

The changes in mass of the composite specimens and changes in both mass and volume of the resin were measured after exposure to the thermal cycles. Four specimens were tested at each interval. Mass was measured using a balance accurate to $10^{-4}$ grams. Volumes were calculated by measuring the length, width, and thickness using digital calipers.
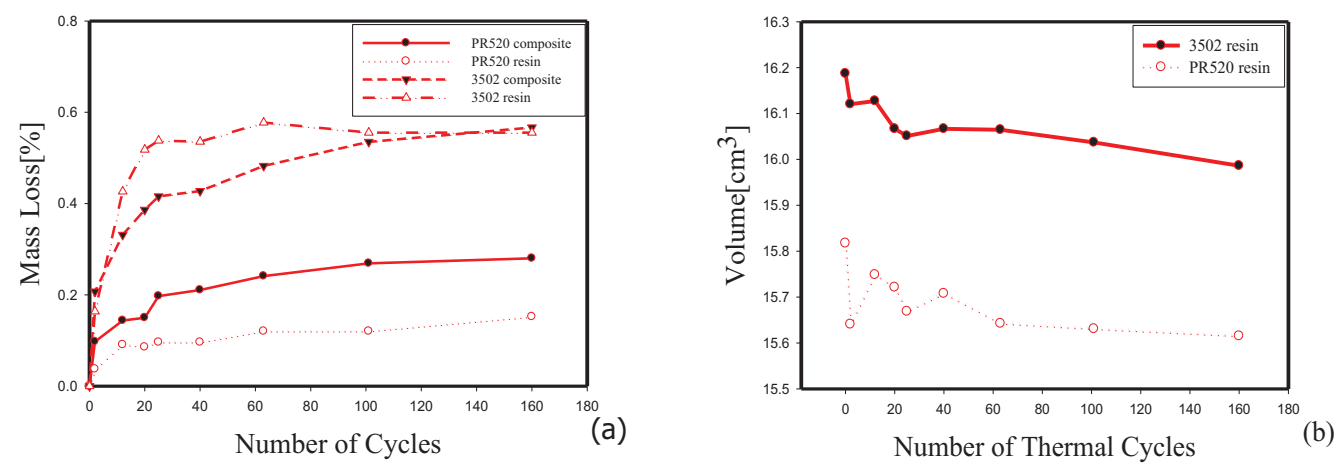

Figure 2: Mass and volume changes versus the number of thermal cycles

Figure 2(a) shows that the changes of mass for both composites and pure resins were small, less than $1 \%$ after 160 cycles. The mass loss was caused by material out gassing. It was reported by Shin et $\mathrm{al}^{[8]}$ that the major out-gassed products were $\mathrm{H}_{2} \mathrm{O}, \mathrm{N}_{2}$ and hydrocarbon. As we can see from the figure, the loss becomes almost flat after 160 cycles. This indicates that no degradation or reaction was causing further loss of mass. Also, we can find that the composites exhibit larger mass loss than resin. This was probably due to more volatile products being trapped in the composite during the manufacturing process. PR520 composite and resin experienced lower mass loss than products made of 3502 resin. Figure 2(b) shows the volume change in the resin versus thermal cycles. There was a significant drop 
of volume during the initial cycles followed by an almost constant, but much smaller, steady state decrease after 60 cycles.

\section{Acoustic Emission Test}

A Digital Wave Corporation (Englewood, CO) Four channel Fracture Wave Detector was used to perform the test. Four Physical Acoustic PICO sensors were mounted on the composite plate with vacuum grease and clipped at locations as shown in Figure 3. Sensors were selected to be small $(5 \mathrm{~mm} \times 4 \mathrm{~mm})$ with respect to the specimen $(50 \mathrm{~mm}$ square) and exhibit a flat frequency response from 200 to $750 \mathrm{kHz}$. Each sensor was connected to a preamplifier and filter trigger module which was connected to a computer. The preamplifier was set at $20 \mathrm{~dB}$, the filter signal was amplified $3 \mathrm{~dB}$, and the filter trigger was amplified $21 \mathrm{~dB}$.

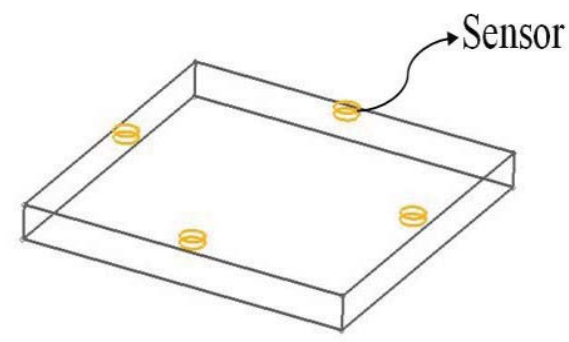

Figure 3: Set-up of acoustic emission sensors
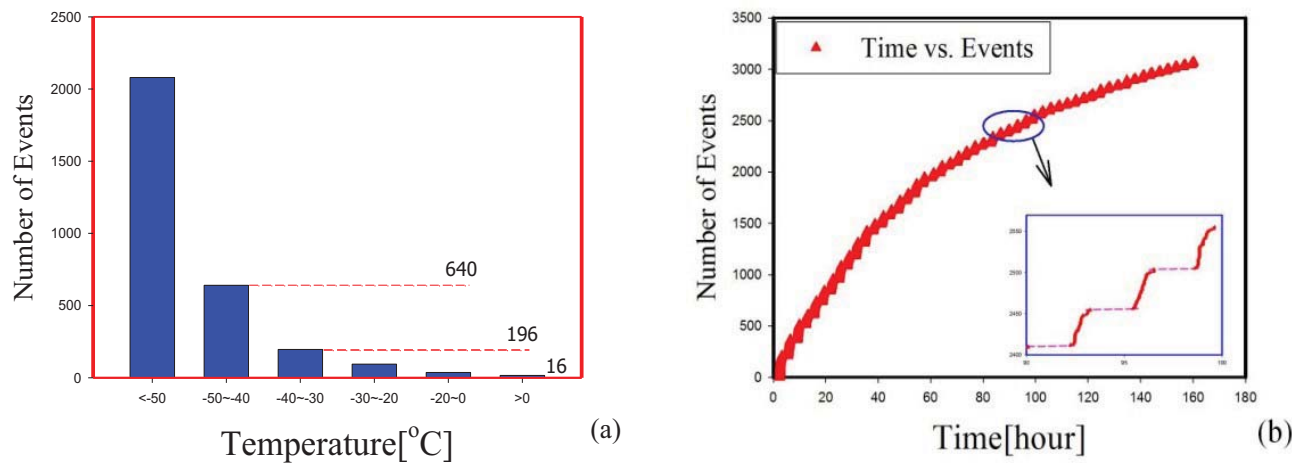

Figure 4: The relationship of acoustic emission events versus temperature (a) and time (b) for the 3502/T700s composite system

For the PR520/T700s composite, no acoustic event was recorded during the first 160 thermal cycles. This indicates that no cracks were formed in the PR520/T700s composite. This was confirmed by the following X-ray CT results. However, for the 3502/T700s composite, up to 3000 events were recorded during the first 50 thermal cycles. Figure 4(b) shows the total number of events accumulated versus time. The total number of events increases in a logarithmic fashion, with a decreasing rate of change, which suggests a possible saturation. Another important observation is that the events seem to happen periodically as shown in the small box 
in Figure 4(b). After checking the corresponding temperatures at those times, it was found that most of the events occurred at the low temperature range. The first event occurred at a temperature of $-54^{\circ} \mathrm{C}$. Figure 4 (a) plots the number of events against temperature. More than $70 \%$ of the events took place at temperatures below $-50^{\circ} \mathrm{C}$; $99 \%$ of the events took place below $0{ }^{\circ} \mathrm{C}$. Especially at the initial stage, the events all happen at the lowest temperature range $\left(<50^{\circ} \mathrm{C}\right)$. The events recorded at the higher temperature are most likely the propagation of the microcracks.

\section{X-ray CT Observation}

$\mathrm{X}$-ray CT was performed on the samples to determine the presence and extent of crack formation. Prior to examination, $18 \mathrm{~mm}$ wide samples were cut from the panels and immersed in a zinc iodide/alcohol/water solution to enhance $\mathrm{x}$-ray contrast. The samples were then inspected using a 3-D computed tomography system consisting of a cone-beam microfocus $\mathrm{x}$-ray source and a flat panel detector. The resulting volumetric CT data was then post-processed using imaging software. Image adjustments were limited to alignment of the volumetric data, re-slicing of the data in the plane of interest and basic contrast enhancement. Figure 5 below shows the contrast enhanced CT results for three samples subjected to 50 thermal cycles. The light lines in the 3502/T700s samples represent areas where the contrast agent was able to penetrate the cracks.

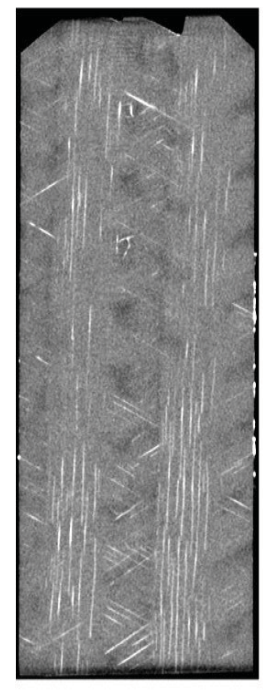

3502/T700s \#1

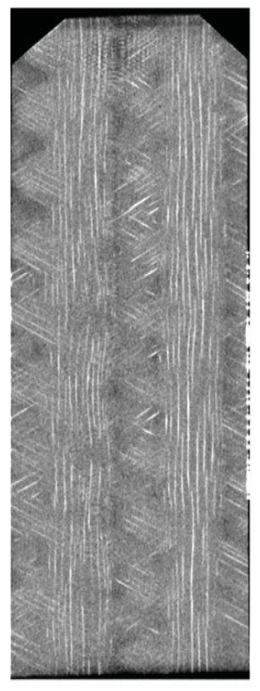

3502/T700s\#2

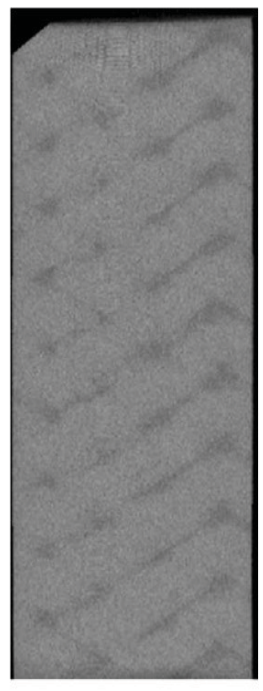

PR520/T700s

Figure 5: Microcracks in the interior plies for 3502/T700s and PR520/T700s after 50 thermal cycles (the white lines in the images are the microcracks)

Figure 5 shows that the main damage in the material was the splitting of fiber bundles and that the microcracks developed in the direction of fiber orientation. This is similar to traditional laminates of which transverse cracks are the main damage induced by thermal cycles ${ }^{[9]}$. The microcracks were reported to span the entire cross section. The three images in Figure 5 show significantly different crack distributions. 
No cracks were detected inside the PR520/T700s composite while microcracks were present throughout the 3502/T700s samples. Although both 3502/T700s specimens were aged over 50 cycles, specimen $\# 2$ developed more microcracks. For 3502/T700s \#1, the crack lengths were shorter, not distributed all over the plane, and the crack density was smaller than for specimen $\# 2$. In the case of 3502/T700s specimen $\# 2$, all microcracks were continuous along the whole cross section and split the entire fiber bundle. Figure 6 shows 3502/T700s \#2 from thickness 0.30 to 0.42 $\mathrm{cm}$ which represents the fourth layer of the sample. The microcracks in each direction go all the way through the fiber bundle and cross over the other fiber bundles without being interrupted by the bundle curvature. The difference in crack distributions for the two 3502 specimens was probably caused by the manufacturing history of cutting and edge polishing. Also the natural spatial variation in the composite properties and internal stresses due to the relative placement of the braid layers may have affected the thermal cycling performance of the specimens.

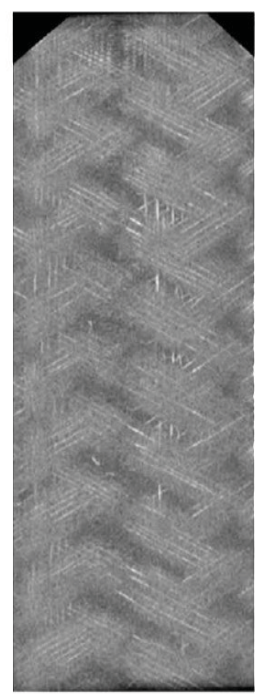

$0.30 \mathrm{~cm}$

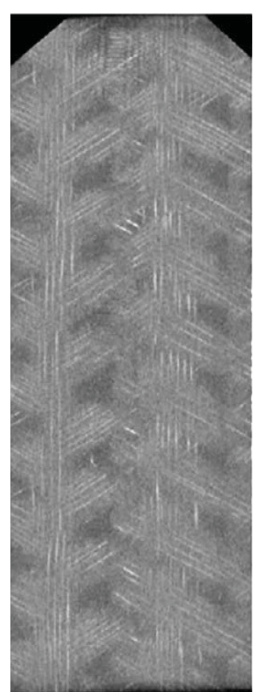

$0.36 \mathrm{~cm}$

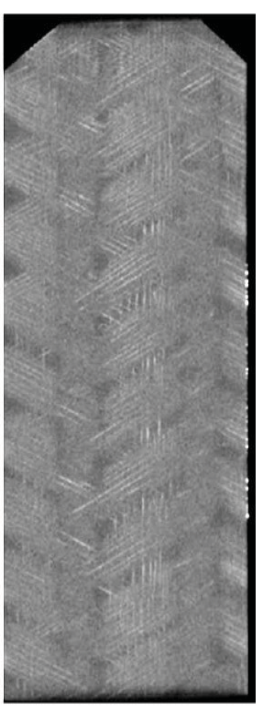

$0.42 \mathrm{~cm}$

Figure 6: Microcracks at different thickness of 3502/T700s \#2 after 50 thermal cycles

According to current results, the composite PR520/T700s has better resistance to thermal cycles. Cycling is still underway. More cycles will give clearer results on the mechanism of microcrack initiation. On the other hand, the history of the material fabrication may affect its performance under the thermal cycling.

\section{Finite Element Model of Thermal Cycling Induced Microcracks}

The analysis of microcracking is important, as it may decrease the effective strength and stiffness of the composite. The damage mechanism of transverse microcracks in composites has been studied extensively in numerous works. Most of the work is for traditional laminates in the framework of finite fracture mechanics. Few of the available models are suitable for braided composites. In this study, finite element simulation was performed to predict the changes of strength and stiffness in $+60^{\circ} / 0^{\circ}$ $60^{\circ}$ braided composites due to microcracking. 
A finite element meso-mechanical model developed by $\mathrm{Li}^{[10]}$ was employed. A double nodes method was used to create microcracks in the three unit cell finite element model as shown in Figure 7 and 8. In Figure 8, the lines along the fiber directions and inside the fiber bundles indicate microcracks. The nodes on the lines were duplicated and assigned individually to the left and right sides of the lines. The perpendicular lines in the \pm 60 degrees sets are frame edges which reflect the slope of the fiber bundles. For braided composite, the crack density could not be defined in the same way as in laminated composites because three different fiber directions were included in each layer. It's more accurate to consider the crack density in each fiber bundle separately. Due to the element size of the meso-mechanical model, a maximum of 6 cracks were inserted in 0 degree fiber bundles and 5 for $\pm 60^{\circ}$ fiber bundles. The maximum crack density was limited to 0.37 and 0.25 for $0^{\circ}$ and $\pm 60^{\circ}$ fiber bundles, respectively.

Several assumptions were made during the modeling work:

1. The composite was assumed to be perfectly bonded and no delamination was considered;

2. Based on the prior experimental results, the microcracks were assumed to be transverse cracks along the three directional fiber bundles;

3. For the axial tension and transverse compression loads, the microcracks in the $0^{\circ}$ direction were ignored in the model as the microcracks tend to close. Similarly, microcracks were ignored in $+60^{\circ} /-60^{\circ}$ for axial compression and transverse tension loads.

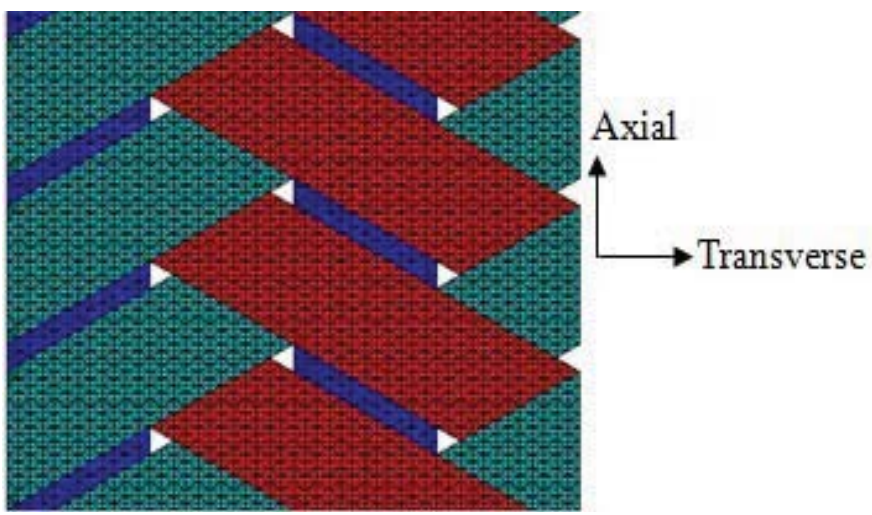

Figure 7: Fiber bundle of the three unit cell meso-mechanical model

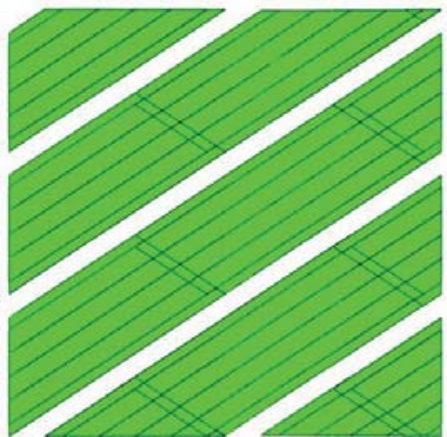

Positive $60^{\circ}$

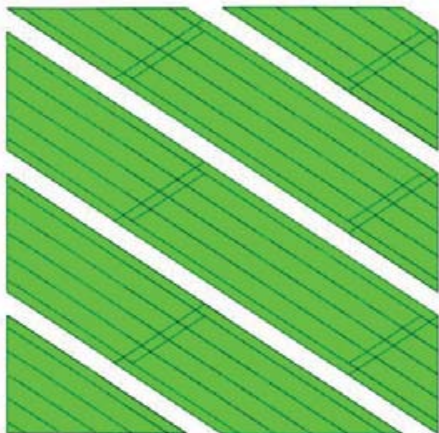

Negative $60^{\circ}$

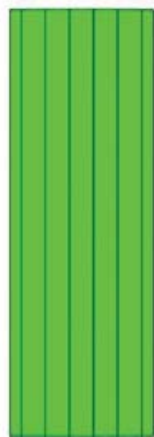

Zero

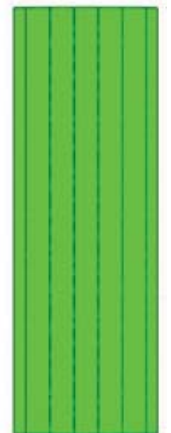

Figure 8: Crack formation in the finite element model 
Table 1: Mechanical properties of fiber bundle

\begin{tabular}{ll}
\hline Carbon/Epoxy fiber bundle & \\
\hline $\mathrm{E}_{\text {longitudinal }}(\mathrm{MPa})$ & 161800 \\
$\mathrm{E}_{\text {transverse }}(\mathrm{MPa})$ & 8600 \\
$\mathrm{G}_{\mathrm{L}}(\mathrm{MPa})$ & 5000 \\
$\mathrm{G}_{\mathrm{T}}(\mathrm{MPa})$ & 2491 \\
$v_{\mathrm{L}}$ & 0.304 \\
$v_{\mathrm{T}}$ & 0.464 \\
$\rho\left(\mathrm{g} / \mathrm{cm}^{3}\right)$ & 1.6 \\
\hline
\end{tabular}

The mechanical properties of the fiber bundle are listed in Table 1. To predict the initial damage, the two-dimensional plane-stress Hashin failure criterion was utilized. The matrix was simply assumed to be an elastic-perfectly plastic material with a modulus of $2700 \mathrm{MPa}$ and strength of $61 \mathrm{MPa}$. To investigate microcrack induced strength and stiffness reduction, both tension and compression simulations of axial and transverse directions were conducted. Symmetric boundary conditions were used the same way as in Li's paper ${ }^{[10]}$ so a two layer plate thickness has been simulated. To obtain the global stress strain curves, displacements along the loading surface were applied and the resulting forces were reported. Since free surfaces were generated where double nodes were used, contact was defined to avoid penetration.

\section{Influence of $0^{\circ}$ microcracks on axial compression and transverse tension}

Figure 9 shows the transverse tension simulation of the microcracked composite. As expected, there was an obvious decrease of both strength and Young's modulus for transverse tension. For the maximum crack density of 0.37 , strength degradation with a $92.7 \%$ residual strength was more serious than a stiffness degradation of $96.3 \%$. Due to convergence problems, the axial compression cases could not be computed long enough to get useable data. Based on the available data for the axial compression case, there was no change in stiffness even for the maximum crack density 0.37 .

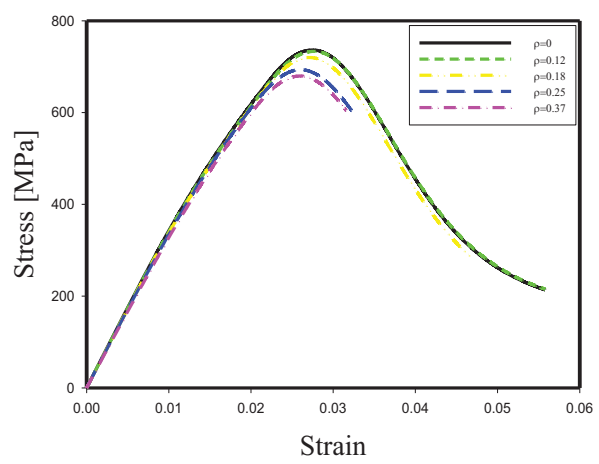

Figure 9: Stress strain curves of transverse tension versus crack density $(\rho)$

\section{Influence of $\pm 60^{\circ}$ microcracks on axial tension and transverse compression}



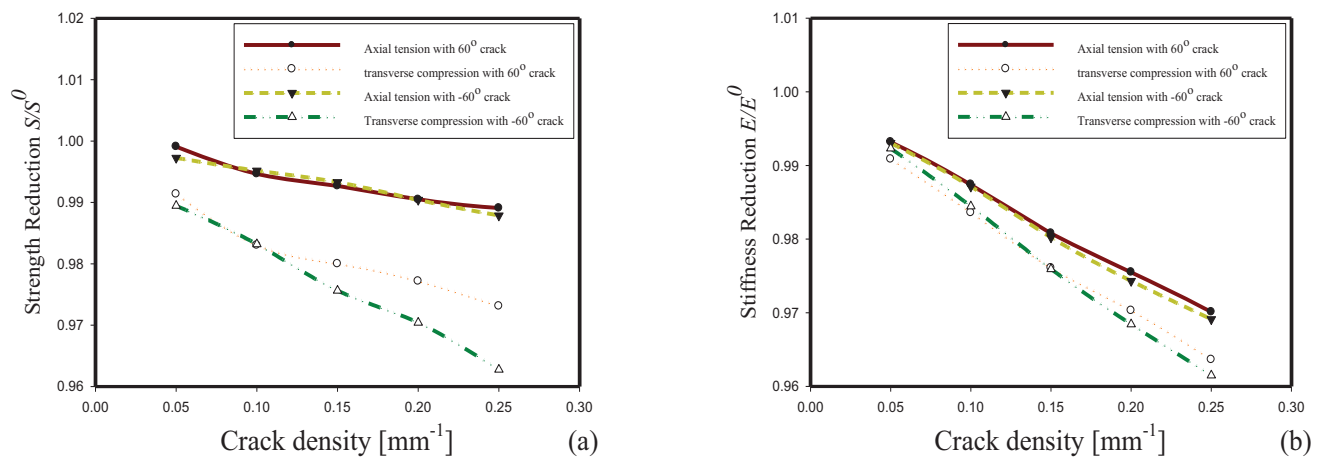

Figure 10: Strength (a) and stiffness (b) reduction versus crack density for composite model with only $+60^{\circ}$ or $-60^{\circ}$ microcracks

The strength and stiffness of both axial tension and transverse compression were expected to be affected by microcracks in $\pm 60^{\circ}$ fiber bundles. In this simulation, the crack densities in $\pm 60^{\circ}$ fiber bundles were assumed to be the same. Before investigating the effective properties of the composite with both direction microcracks, the influences of $\pm 60^{\circ}$ fiber bundles were studied separately. Figure 10 plots the strength and stiffness reduction of the composite that has only +60 or -60 degree microcracks. As we can see from the figure above, the strength and stiffness decrease almost linearly with the increase in crack density. The reduction percentages of transverse compression were more than those of axial tension; strength has higher resultant percentages than stiffness which is opposite from the 0 degree microcrack cases. Combined with the results in Figure 9, we can conclude that microcracks may result in more serious property reductions in the transverse direction. Comparing the plots of +60 and -60 degree cracks, a slightly higher reduction in the axial tension simulation was caused by $-60^{\circ}$ microcracks while the difference tends to be larger for transverse compression along with the crack density. Considering there was some difference of the $+60^{\circ}$ and $-60^{\circ}$ fiber bundle geometry in the model, this small difference can be ignored and $+60^{\circ}$ and $-60^{\circ}$ microcracks can be considered to have the same reduction effects on the properties.

Including both $\pm 60^{\circ}$ direction microcracks in the model, the relationship of crack density on the strength and stiffness reduction for axial tension and transverse compression is plotted in Figure 11. The crack density in the figure is the value of both $\pm 60^{\circ}$ direction microcrack densities. Transverse compression also showed higher reduction percentages than the axial tension simulations. For the maximum crack density, the resultant strength and stiffness percentage of transverse compression would decrease to $94.3 \%$ and $93.0 \%$, respectively. The property degradation was not very serious for the current crack densities. Further work will investigate the influences of higher crack density. 

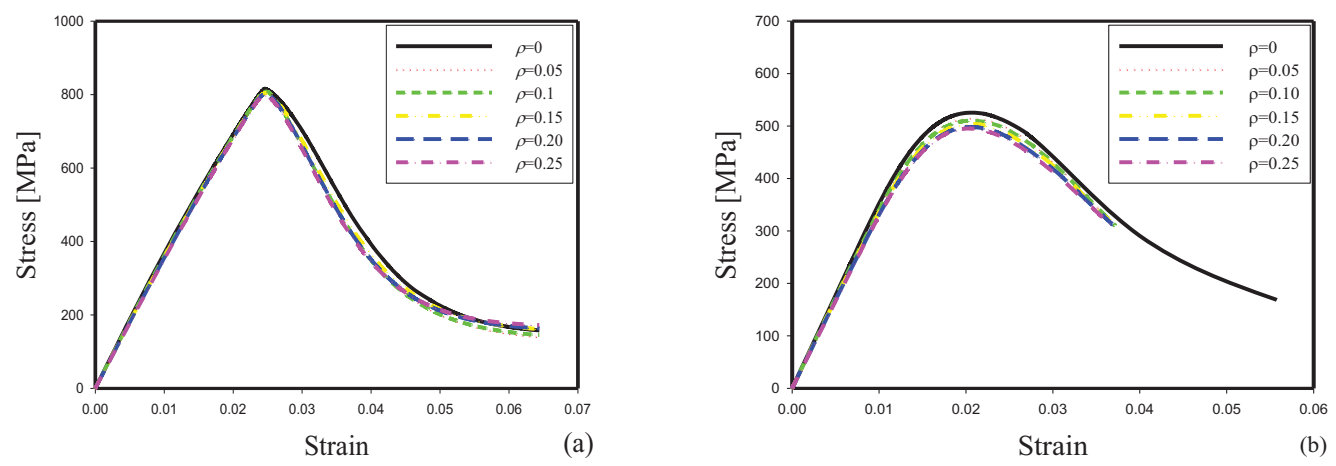

Figure 11: Stress strain curves of axial tension (a) and transverse compression (b) versus crack density

\section{Conclusions}

3502/T700s and PR520/T700s graphite/epoxy triaxial braided composites have been evaluated following exposure to thermal cycling between $-55^{\circ} \mathrm{C}$ and $120^{\circ} \mathrm{C}$. The mass and volume changes of composites and resins after 160 cycles were less than $1.0 \%$. According to results of both the Acoustic Emission and X-ray CT tests, no microcracks were detected in PR520/T700s composites. The AE events of $3502 /$ T700s showed a logarithmic curve versus time and occur periodically at the low temperature range. The first event was found to occur at a temperature of $-54^{\circ} \mathrm{C}$. The X-ray CT results showed microcracking damage throughout the thickness of the six layer samples. The cracks in the form of splitting of fiber bundles were present in all three fiber directions.

A finite element meso-mechanical model was utilized to simulate the influence of microcracks on the effective strength and stiffness of the braided composite. The strength and stiffness followed an inverse relation to crack density. Transverse properties were found to experience more degradation compared with axial properties. In the current model, for a maximum $0^{\circ}$ crack density of 0.37 and a maximum $\pm 60^{\circ}$ crack density of 0.25 , the resultant stiffness and strength percentages were all more than $92 \%$.

Further experiments and simulations are underway to investigate the relationship of crack density and thermal cycles, as well as to study the property reductions for an FEA model with higher crack density.

\section{Reference}

1. Roberts, G. D., Pereira, J. M., Revilock, D. M., Binienda, W. K., Xie, M.,and Braley, M. (2003), Ballistic impact of composite plates and halfrings with soft projectiles, Proc., 44th AIAA/ASME/ASCE/AHS Structures, Structural Dynamics, and Materials Conf., Norfolk, Va.

2. SA Eselun, HD Neubert and EG Wolff (1979), Microcracking effects on dimensional stability, 24th National SAMPE Symp Proc, pp. 1299-1309. 
3. M.C. Lafarie-Frenot, N.Q. Ho (2006), Influence of free edge intralaminar stresses on damage process in CFRP laminates under thermal cycling conditions, Composites Science and Technology 66, 1354-1365

4. M.C. Lafarie-Frenot, S. Rouquie (2004), Influence of oxidative environments on damage in c/epoxy laminates subjected to thermal cycling, Composites Science and Technology 64, 1725-1735

5. C. Henaff-Gardin, M.C Lafarie-Frenot (2002), Specificity of matrix cracking development in CFRP laminates under mechanical or thermal loadings, International Journal of Fatigue 24, 171-177

6. Cohen D, Hyper M.W., Tompkins S.S. (1984), The effects of thermal cycling on matrix cracking and stiffness changes in composite tubes, National Technical Conference, 16th, Albuquerque, NM, United States, 9-11.577-588

7. Seehra S, Benton D, Rosen J, Gounder R (1985). Effects of space environmental conditions on graphite epoxy composites. SAMPE Journal 21(2):18-23

8. Kwang-Bok Shina, Chun-Gon Kima, Chang-Sun Honga, Ho-Hyung Leeb (2000), Prediction of failure thermal cycles in graphite/epoxy composite materials under simulated low earth orbit environments, Composites: Part B 31 223-235

9. Daniel S. Adams, David E. Bowles and Carl T. Herakovich (1986), Thermally Induced Transverse Cracking in Graphite-Epoxy Cross-Ply Laminates, Journal of Reinforced Plastics and Composites 5: 152-169

10. Wieslaw K. Binienda and Xuetao Li (2010), Mesomechanical Model for Numerical Study of Two-Dimensional Triaxially Braided Composite, J. Eng. Mech. $136,1366-1379$ 